\title{
The Ascending Pharyngeal Artery of the Dog
}

\author{
By \\ Tadaaki MORI \\ Department of Anatomy, Osaka Dental University, \\ 1-47, Kyobashi, Higashi-ku, Osaka, 540, Japan \\ (Director: Prof. Y. Ohta) \\ (with 1 textfigure, 2 tables and 17 figures in 4 plates) \\ -Received for Publication, May 31, 1985.-
}

Key words: Ascending pharyngeal artery, Pharynx, Plastic injection, Comparative anatomy, Dog.

Summary: The ascending pharyngeal artery of the dog was investigated by means of the acryl plastic injection method. This artery usually arose from the external carotid artery, sometimes from the occipital, the posterior auricular, or rarely the ascending palatine of the lingual artery. It ran forwards between the vagus and hypoglossal nerves and continued anteromedially up to the posterolateral wall of the pharynx at the superior margin of the thyropharyngeus muscle, in contact with the inferomedial end of the tympanic bulla. En route it gave rise to the thyropharyngeal, the stylopharyngeal and the styloglossal branches, sometimes additionally the inferior cervical, the digastric and the palatine branches, although all these branches were not observed when it arose from the lingual. It reached to the inferomedial end of the foramen caroticum externum after giving rise to twigs to the pharyngeal mucosa between the pharyngeal opening of the auditory tube and the pharyngeal isthmus, and the stylopharyngeal, the hypopharyngeal, the levator veli palatine, the thyropharyngeal and the styloglossal branches between the stylopharyngeus and the styloglossus muscles and inferomedial to the tympanic bulla. From this position, the ascending pharyngeal passed above the opening of the auditory tube in about half of all examples observed towards this foramen, but did not intertwine around the loop of the internal carotid. Rarely, it anastomosed with the inferoanterior end of the loop. The main stem of this artery ran forwards between the pterygoid process and the superior wall of the nasopharynx, and gave off small twigs anastomosing with the opposite fellows in the mucosa of the pharyngeal fornix. Finally, it was distributed to the mucosa around the choanae beyond the pterygopalatine suture. In one case, it terminated on the superior margin of the thyropharyngeus muscle, and a branch arising from the loop of the internal carotid divided into the anterior and posterior twigs. The former supplied the mucosa of the nasopharynx, while the latter the levator veli palatini, the thyropharyngeus and the thyroglossus muscles. In conclusion, it can be said that this artery of the dog never contributed to the blood supply of the brain at all, although the ascending pharyngeal of some carnivorae actually constituted a collateral route of the internal carotid, and has probably been presented as a similar vessel in the embryological period of other species. 
The ascending pharyngeal artery of the dog was first described by Ellenberger et al. (1891). There have been subsequent investigations on the ramifications and supplying features of this artery in the palate and pharynx. In these works, various observations were made and conclusions reached on such questions, especially concerning communicating patterns between this vessel and the internal carotid. The descriptions of some scholars indicated an exactly constant communication, but both vessels were said to be interwined with each other without real anastomosis by others. The former analysis suggested that the ascending pharyngeal contributed generally to the blood supply of the brain in the dog as in the cat, in that the internal carotid was usually defective.

The present work will deal with detailed investigations of the ramifications and distribution features of the ascending pharyngeal of the dog, determining the names of the branches and paying special attention to the relations between this vessel and the internal carotid.

\section{Materials and Methods}

Seventy adult dogs were used. Acryl plastic was injected via the common carotid arteries utilizing the plastic injection method (Taniguchi, Ohta and Tajiri 1952, 1955) in all 70 heads. Sixty of the heads were prepared to corrosion specimens of the carotid system after dissolving tissues for observation and measurement of the vascular structure. The other 10 heads were fixed in formalin for dissection.

\section{Findings}

The external carotid artery $(2.1 \sim 4.5$, M.3.15mm in diameter) ran forwards between the digastricus muscle and the pharyn- geal wall, and gave rise to the occipital artery $1 \sim 6 \mathrm{~mm}$ distal to "its origin, and the lingual artery $5 \sim 8 \mathrm{~mm}$ distal to it. In two cases, the posterior auricular artery diverged from the external carotid at the height of origin of the occipital artery.

The ascending pharyngeal artery $(0.5, \sim$ $1.4, \mathrm{M} .0 .82 \mathrm{~mm}$ in diameter) arose from the above-mentioned arteries, displaying the following relations. This artery arose from the anterior or medial wall of the occipital $(0.9 \sim 1.5$, M. $1.14 \mathrm{~mm}$ in diameter) immediately after its origin in 62 of all 120 examples observed (Figs. 1, 2), and directly from the medial, mediosuperior or superior wall of the external carotid in 54 (Figs. 1, 3). In the two above cases in which the occipital and the posterior auricular arose at the same height, the ascending pharyngeal arose from the medial wall of the posterior auricular immediately after its origin (Fig. 4). It arose from the ascending palatine $(0.9 \mathrm{~mm}$ in diameter) of the lingual in one case (Fig. 5) and from the occipital arising from the internal carotid (Fig. 6) in one case.

The ascending pharyngeal passed forwards between the vagus and hypoglossal nerves, superomedial to the external carotid, and turned anteromedially anterior to the internal carotid to cross in front of the pharyngeal branch of the vagus. It reached the superior margin of the thyropharyngeus muscle in the lateral wall of the pharynx via the inferomedial end of the tympanic bulla (Figs. 2, 3). This was located superomedial to the origin of the lingual and medial to the crossing between the stylopharyngeus muscle and the external carotid. En route the artery gave rise to the inferior cervical branch medially in 25 (Fig. 4), the digastric branch anterolaterally in 39 (Fig. 7), and the thyropharyngeal branch in 118 (Fig. 3). In 9 it gave off the palatine branch inferomedially (Figs. 2, 8) and a small twig $(0.23 \mathrm{~mm}$ in diameter $)$ to the 


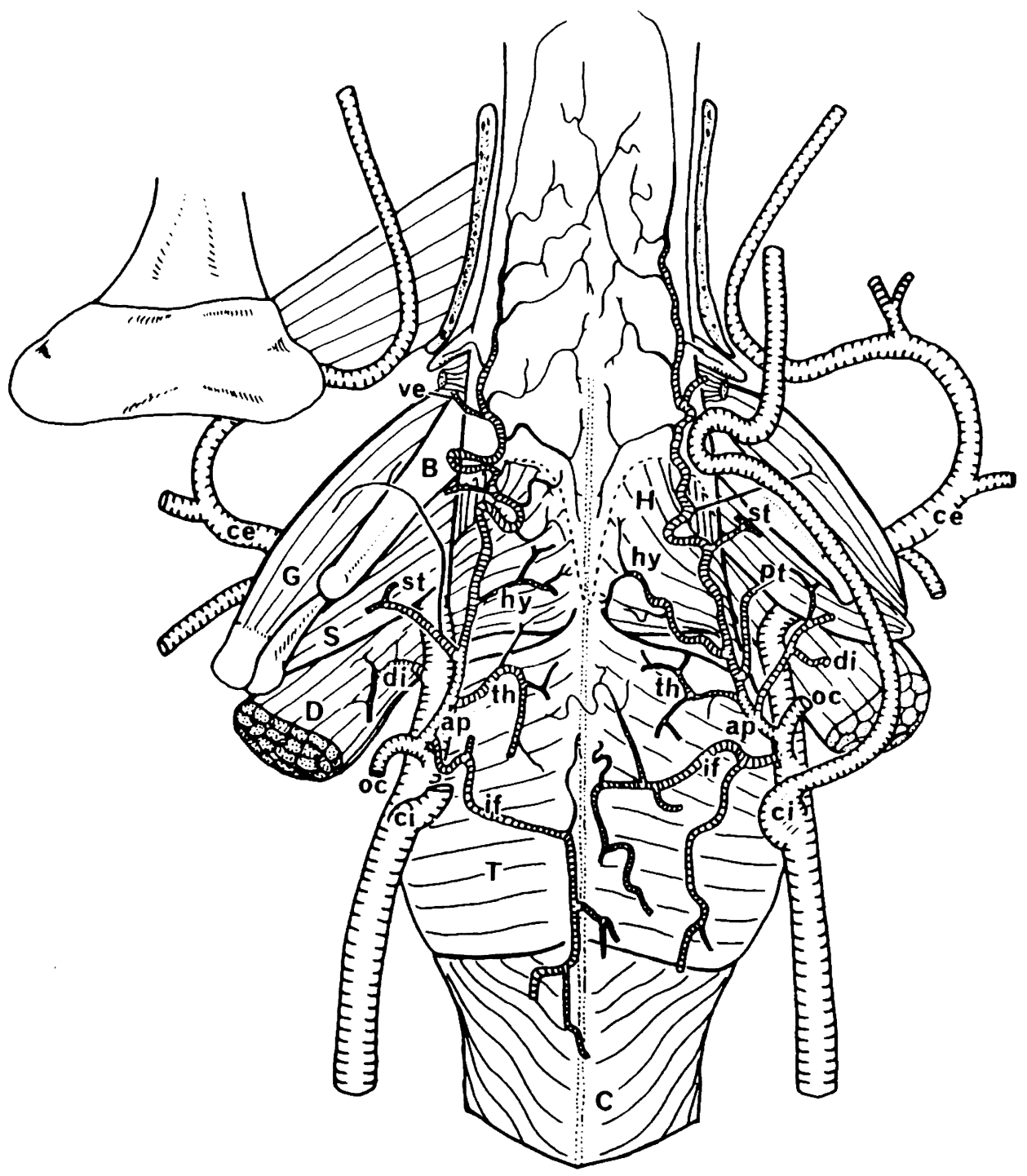

Fig. 1. The whole distribution features of the ascending pharyngeal artery on the posterior wall of the pharynx.

ap: Ascending pharyngeal artery

B: Stylohyoid bone

C: Cricopharyngeus muscle

ce: External carotid artery

ci: Internal carotid artery

D: Digastricus muscle

di: Digastric branch

$\mathrm{G}$ : Stylohyoideus muscle

$\mathrm{H}$ : Hyopharyngeus muscle hy: Hyopharyngeal branch

if: Inferior cervical branch

oc: Occipital artery

pt: Palatine branch

S: Stylopharyngeus muscle

st: Stylopharyngeal branch

T: Thyropharyngeus muscle

th: Thyropharyngeal branch

ve: Levator veli palatine branch 
stylopharyngeus and styloglossus muscles anterolaterally in 102 (Fig. 8). In one case in which the origin of this artery was located considerably inferoanteriorly, it did not give rise to any of the above mentioned branches (Fig. 5).

The ascending pharyngeal continued to pass forwards inferomedial to the tympanic bulla between the lateral margin of the posterior wall of the pharynx, the stylopharyngeus and styloglossus muscles tortuously, up to the inferomedial end of the foramen caroticum externum in 119 cases (Fig. 9). En route it gave rise to the hyopharyngeal branches and to two to four small twigs $(180 \mu \mathrm{m}$ in diameter) which supplied the mucosa between the opening of the auditory tube and the pharyngeal isthmus in the posterior half of the nasopharynx (Figs. 9, 10). Sometimes, these twigs passed laterally beneath the parent artery to supply the osseous wall of the bulla (Fig. 9). In addition, the ascending pharyngeal gave rise to the distal, stylopharyngeal branch and to small twigs $(190 \mu \mathrm{m}$ in diameter) to the levator veli palatini and the styloglossus muscles laterally (Fig. 10).

In 75 of the above 119 cases, the ascending pharyngeal passed forwards above the opening of the auditory tube and medial to the loop of the internal carotid, without intertwining with it in the foraman caroticum externum (Fig. 9). In 40 cases, it made an upward curvature $(1 \sim 2 \mathrm{~mm}$ in height and $0.5 \mathrm{~mm}$ in diameter) towards the foramen medial or anterior to the loop, but did not intertwine with it (Fig. 11). In 23 of the above 40 cases, it gave off small twigs $(400 \mu \mathrm{m}$ in diameter) into the foramen posterosuperiorly, which supplied the periosteum around it (Fig. 12). However, these fine branches of the ascending pharyngeal at first sight appeared to be intertwined around the loop, which was surrounded tightly by a complicated venous plexus. In 4 of the above 119 cases, the artery appa- rently anastomosed with the anteroinferior end of the loop, from which a small twig (700 $\mu \mathrm{m}$ in diameter) diverged as it appeared to be a continuation of the ascending pharyngeal (Fig. 13).

In its final course, the artery passed straightly forwards between the pterygoid process of the sphenoid bone and the superior wall of the nasopharynx (Fig. 9), and supplied the mucosa around the choanae beyond the pterygopalatine suture. En route it gave off small twigs $(120 \mu \mathrm{m}$ in diameter $)$ to the mucosa of the pharyngeal fornix, which anastomosed with the opposite fellows network-wisely (Fig. 14).

In only one of all 120 examples observed, did the ascending pharyngeal $(500 \mu \mathrm{m}$ in diameter) arise from the external carotid at the height of the superior margin of the thyropharyngeus muscle in the posterolateral wall of the pharynx, and terminated after giving off the thyropharyngeal, the stylopharyngeal and the palatine branches. A branch $(500 \mu \mathrm{m}$ in diameter) arose from the anteroinferior end of the loop of the internal carotid and immediately divided into the anterior $(120 \mu \mathrm{m})$ and posterior twigs $(500 \mu \mathrm{m})$. The former supplied the levator veli palatini and the mucosa of the pharyngeal fornix, and the latter meandered backwards along the lateral margin of the superior pharyngeal wall and medial to the loop, and spread to the hypopharyngeal, the thyropharyngeal and the styloglossal branches. That is, the usual distribution territory of the ascending pharyngeal was completely covered by short corresponding vessels, but no anastomoses were observed between them (Fig. 15).

\section{Inferior cervical branch}

This branch $(0.6 \sim 1.1, \mathrm{M} .0 .87 \mathrm{~mm}$ in diameter) arose from the occipital in 51 of all 120 examples observed (Figs. 3, 8), from the cranial thyroid in 30 (Fig. 16), from the ascending pharyngeal in 25 (Figs. 4, 18), 
and directly from the external carotid in 14 (Fig. 8).

In 11 of the above 25 cases, the ascending pharyngeal arose from the occipital (from the internal carotid in 1 case), and in the remaining 14 from the external carotid (Table 1). In 20 of all 120 cases observed, no difference in thickness was found between the branches of both sides. This branch passed medially beneath the internal carotid and the vagus nerve, and bent backwards medial to this nerve in the posterior wall of the pharynx. It then again turned medially at right angles at the height of the bifurcation of the common carotid artery to come between the longus capitis and the thyropharyngeus muscles, passing through the lateral margin of the longus capitis up to the median line, where it anastomosed with the opposite fellow. En route it gave rise to two or three twigs $(490 \mu \mathrm{m}$ in diameter) anteriorly and posteriorly. The former supplied the insertion of the longus capitis, the hyopharyngeus and the mucosa of the laryngeal region of the pharynx, and the latter supplied the longus capitis. The branch bent backwards between the longi capiti of both sides along the pharyngeal raphe. Giving off numerous twigs $(480 \mu \mathrm{m}$ in diameter) to these muscles, it finally divided into two. The one $(610 \mu \mathrm{m})$ supplied their insertion, anastomosing with the muscular branch of the cervical branch of the occipital. The other $(450 \mu \mathrm{m})$ supplied the same muscle of the opposite side beyond the median line and their insertions on both sides (Fig. 17).

In the remaining 100 , this branch was so underdeveloped on one side that it did not reach up to the median line. Reversely, it was so well-developed on the other side that it extended beyond the median line and followed a similar course to that mentioned above (Fig. 18).

\section{Digastric branch}

This branch $(0.5 \sim 1.0, M .0 .71 \mathrm{~mm}$ in diameter)arose laterally from the superior wall of the external carotid, distal to the origin of the occipital (Fig. 5) in 81 cases, while, in the other 39 cases it arose anterolaterally from the superior or lateral wall of the ascending pharyngeal and immediately bent laterally to pass above the external carotid (Fig. 7). This branch was distributed to the origin of the digastricus muscle, sometimes the thyropharyngeus additionally, and gave rise to the stylopharyngeal branch (Fig. 7).

\section{Thyropharyngeal branches}

The branches $(0.3 \sim 0.7, \mathrm{M} .0 .49 \mathrm{~mm}$ in diameter), numbered one to three (one in 95 , two in 22 , three in 1) in 118 of all 120 examples observed, arose medially from the medial or inferior wall of the ascending pharyngeal. In 6 of these cases, the vessel was rather thinner and a similar branch arising from the inferior cervical branch was noted (Fig. 3). In two of all examples observed, it arose from the laryngeal artery. They passed anterosuperiorly between the thyropharyngeus and the longus capitis to supply them, and terminated in the mucosa covering the hyopharyngeus and the posterior wall of the pharynx. They never extended to the other side beyond the median line. When their origins were situated distally, they arose medially to supply the thyropharyngeus and the mucosa mentioned above.

\section{Palatine branch}

This branch $(0.36 \sim 0.6$, M. $0.51 \mathrm{~mm}$ in diameter) usually arose from the lingual except 19 in which it arose from the ascending pharyngeal (Fig. 2). In these 19 cases, it arose inferoanteriorly from the inferior wall of this artery and passed forwards between the hyopharyngeus and the stylopharyngeus to supply them, up to the anterior margin of the stylopharyngeus, where it 
divided into the anterior $(0.43 \mathrm{~mm}$ in diameter) and the inferior $(0.46 \mathrm{~mm}$ in diameter) (Fig. 8). The former continued forwards medial to the stylopharyngeus to supply it, and finally reached to a position lateral to the palatine tonsil to supply it and the mucosa of the palatoglossal arch (Fig. 8). The latter descended medial to the styloglossus to supply it and the mucosa of the soft palate, anastomosing with the tonsillar branches of the ascending palatine.

\section{Stylopharyngeal branch}

The branch $(0.28 \sim 0.62, \mathrm{M} .0 .39 \mathrm{~mm}$ in diameter) arose near or distal to the origin of the ascending pharyngeal. In the former case, in 102 of all examples observed, it arose anterolaterally from its inferolateral wall in the height of the stylopharyngeus in the lateral wall of the pharynx (Fig. 6), and passed laterally above the external carotid to supply the stylopharyngeus and the origin of the styloglossus passing between the tympanic bulla and this muscle. In 14 of the remaining $18 \mathrm{cases}$, it arose from the digastric branch of the external carotid (Fig. 7). In another two of the above 18 cases, it directly arose from the external carotid, in another one from the posterior auricular, and in the one remaining case from the occipital, being similar to the former in its distribution features. The latter, arising distally, when the parent artery passed medial to the tympanic bulla on the lateral margin of the pharynx, left its lateral, medial or inferior wall and supplied the stylopharyngeus and the styloglossus (Fig.3).

\section{Hy opharyngeal branch}

This branch $(0.21 \sim 0.50$, M. $0.36 \mathrm{~mm}$ in diameter) in all examples observed arose anteromedially from the medial wall of the ascending pharyngeal and passed medially between the longus capitis and the hyopharyngeus, giving off many twigs to them, the stylopharyngeus and the mucosa of the pharyngeal isthmus (Fig. 3). It was rather thin when small twigs of the stylopharyngeal branch or of the inferior cervical branch were well-developed (Fig. 9).

\section{Levator veli palatine branch}

This branch $(0.2 \sim 0.32, \mathrm{M} .0 .23 \mathrm{~mm}$ in diameter) in all examples observed arose laterally from the lateral wall of the ascending pharyngeal at right angles and supplied the origin of the levator veli palatini (Fig. 10).

\section{Discussion}

The ascending pharyngeal artery usually arose from the external carotid or the occipital near its origin as indicated by Azuma (1960), Suzuki (1965), Kamakura (1970) and Evans et al. (1979). In addition to these origins, the present author observed that they could be located on the maxillary artery in common with the posterior auricular, on the internal carotid in common with the occipital, and on the ascending palatine. The origins in the former and middle cases were located at the usual height, since the origin of the posterior auricular was located proximally in the former. Since the origin of the occipital was located on the internal carotid in the middle case, the origin of the ascending pharyngeal arose via a common trunk with the occipital. Exceptionally, the origin of the latter had shifted itself anteriorly.

Ellenberger et al. (1891) stated that the ascending pharyngeal arose from the common carotid near the origin of the superior thyroid artery. The present author, however, could not observe such an origin as described by Azuma.

The present author surveyed the variations in the ascending pharyngeal in comparison with the findings described by previous inves- 
Table 2. Origins of the ascending pharyngeal artery in the dog and man

\begin{tabular}{|l|l|c|c|c|c|c|c|c|}
\hline \multirow{2}{*}{} & \multirow{2}{*}{ Investigators } & \multicolumn{7}{|c|}{ Parent arteries } \\
\cline { 3 - 9 } & Occipital & $\begin{array}{l}\text { External } \\
\text { carotid }\end{array}$ & $\begin{array}{l}\text { Posterior } \\
\text { auricular }\end{array}$ & $\begin{array}{l}\text { Ascending } \\
\text { palatine }\end{array}$ & $\begin{array}{l}\text { Internal } \\
\text { carotid }\end{array}$ & Maxillary & Others \\
\hline \multirow{3}{*}{ Dog } & Azuma & 78.3 & 21.7 & & & & & \\
\cline { 2 - 10 } & Kamakura & 41.7 & & & & & & \\
\cline { 2 - 10 } & Mori & 51.7 & 45.0 & 1.7 & 0.8 & $0.8^{* 1}$ & & \\
\hline \multirow{2}{*}{ Man } & Adachi & 23.0 & 66.4 & & & 8.8 & 0.9 & $0.9^{* 2}$ \\
\cline { 2 - 9 } & Aratani & 20.0 & & & & & & \\
\hline
\end{tabular}

*1 In common with the occipital artery

*2 From a communicating branch between the common carotid and internal carotid arteries

tigators. As shown in Table 2, the frequency of its origin being located on the occipital was found to be twice as great in the dog as in man. Although its origin located on the maxillary was indicated in man by Kamijo (1966) and in Gray's Anatomy (Warwick 1973), the present author did not find such a case in the dog.

The origin of the ascending pharyngeal has a close relationship with that of the occipital in the cat and dog, as stated by Tandler (1899), Hürlimann (1913), Norris (1906), Davis et al. (1943), Daniel et al. (1953), Azuma (1960) and Martínez (1965). In the cat, the ascending pharyngeal arose from the small nipple-like internal carotid (Davis et al.) in the usual pattern. Such a pattern found in only one case of the dog in this paper that is an interesting feature in the comparative anatomy.

One of branches of the ascending pharyngeal was named the pharyngeal branch by Nickel et al.(1976) and Evans et al. (1979). The present author did not assign this route under the name of the pharyngeal branch, because this would be a route supplying blood to the pharynx according to its own name, and the present author was able to confirm that its termination actually reached to the pharyngeal fornix.
The relations between the ascending pharyngeal and the loop of the internal carotid will now be discussed. Evans et al. reported that the ascending pharyngeal terminated after anastomosing with the loop of the internal carotid. In this paper the exact anastomosis between the vessels was found in only 3.3\%. Jewell (1952) and Daniel et al. recognized the presence of this anastomosis as described by some scholars. Kaneko (1970) stated that both vessels were intertwined with each other. An alternative case was one in which a branch arising from the loop supplied the usual area supposed to be covered by the usual ascending pharyngeal, but did not anastomose with peripheries of it. Viewed in terms of this special case, the ascending pharyngeal that had anastomosed formerly with the internal carotid would be cut off at the communicating site as the whole skull have grown. Evans et al. cited a description in which the distal end of the ascending pharyngeal appeared to show a pattern just like the internal carotid in the cranial cavity of the adult cat in the paper of Davis et al. The present author will attempt to discuss this item based on his own findings as follows. The rete mirabile of the maxillary artery of the cat supplies blood to the brain in 
place of the internal carotid and the stapedial arteries (Tandler) as noted by Takemura (1982). From the special case of the dog mentioned above, it is suggested that the ascending pharyngeal could be a collateral route to the brain in the embryological period in a position proximal to the rete of the cat as well as the $r$. anastomoticus and a. anastomotica of the dog. It is, however, obvious that this vessel does not con- tribute to the blood supply of the brain in the adult dog.

In the present paper, the digastric, the thyropharyngeal, the stylopharyngeal, the hyopharyngeal and the levator veli palatine branches were found to be supplemented as constant branches of the ascending pharyngeal artery.

The first branch of this artery was the inferior cervical branch corresponding to the

Table 1. Arising features of the ascending pharyngeal artery and the inferior cervical branches

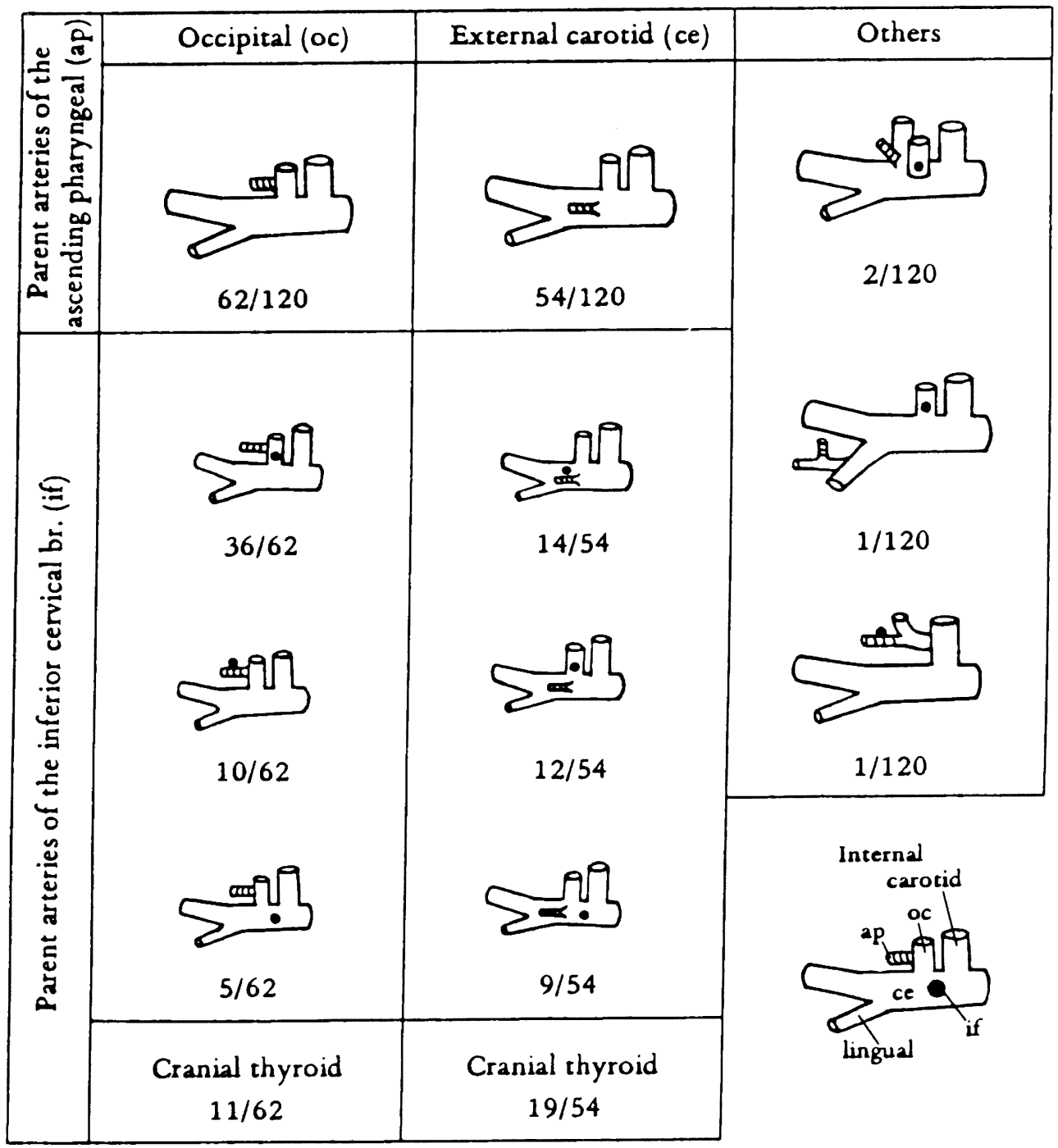

ap: Ascending pharyngeal artery

ce: External carotid artery if: Inferior cervical branch

oc: Occipital artery 
same named one of the occipital described by Ellenberger et al. and Suzuki (1963), as well to the muscular branch of the cranial laryngeal or the cricothyroid branch of a large muscular branch by Evans et al., and also probably to a small twig by Bradley (1927). As indicated in the present paper, the origin of the inferior cervical branch was observed on the occipital, the cranial thyroid, the ascending pharyngeal and the external carotid in descending order of frequency as shown in Table 1 . It was confirmed that its distribution territory did not change even if such variations were seen in its origin.

The palatine branch was found in only $10 \%$ of all examples observed, although it was noted in all examples of Azuma and Evans et al. In short, its origin was located on the lingual artery in the remaining $90 \%$. Evans et al. reported it as several small twigs. He may have include the levator veli palatine branch of the present author.

The digastric and the levator veli palatine branches have not so far been reported. Evans et al. indicated the thyro-, the styloand the hyopharyngeal branches as the pharyngeal branches. Ellenberger et al. and Suzuki did not indicate such nomenclatures, but gave a statement of their distribution areas.

The author wishes to express his thanks to Professor Y. Ohta, Assistant Professor T. Tokioka and Assistant F. Suwa for their guidance and encouragement.

\section{References}

1) Adachi, B.: Das Arteriensystem der Japaner. Bd. 1, Maruzen, Kyoto, 78-80, 1928.

2) Aratani, R.: Studies on the external carotid artery in the Japanese-occipital artery. Stud. Dept. Anat. Tokyo Dent. Coll. (Tokyo Shika Daigaku Kaibogaku Kyoshitsu Gyosekishu), 15: 339-349, 1960 (in Japanese).

3) Azuma, I.: Cubical anatomy of several ducts and vessels by injection method of acrylic resin. XI. Arterial distribution of the palatine tonsil in some mammals. Okajimas Folia Anat. Jpn., 37 : 183-208, 1960.

4) Bradley, O.C.: Topographical anatomy of the dog. 2nd ed., Oliver \& Boyd, London, 182, 1927.

5) Daniel, P.M., J.D.K. Daves and M.M.L. Prichard: Studies of the carotid rete and its associated arteries. Philos. Trans. Roy. Soc., Lond on, 237 (B): 173-208, 1953.

6) Davis, D.D. and H.E. Story: The carotid circulation in the domestic cat. Zool. Series Field Mus. Nut. Hist., 28: 1-47, 1943.

7) Ellenberger, W. und H. Baum: Systematische und topographische Anatomie des Hundes. Paul Parey, Berlin, 373-375, 1891.

8) Evans, H.E. and G.C. Christensen: Miller's anatomy of the dog. 2nd ed., W.B., Saunders, Phila. and London, 654-692, 1979.

9) Hürlimann, R.: Die arteriellen Kopfgefässe der Katze. Intern. Mschr. Anat. Physiol., 29 : 382-383, 1913.

10) Jewell, P.A.: The anatomoses between internal and external carotid circulations in the dog. J. Anat., 86: 83-94, 1952.

11) Kamakura, K.: Stereological Studies on Several Ducts and Vessels by Injection Method of Acrylic Resin. XXV. On the occipital artery in some mammals. Okajimas Folia Anat. Jpn., 47: 287-317, 1970.

12) Kamijo, Y.: Oral anatomy. vol. 3, Angiology. Anatom, Tokyo. 411-443, 1966 (in Japanese).

13) Kaneko, S.: Stereological Studies on the Several Ducts and Vessels by Injection Method of Acrylic resin. XXIV. On the internal carotid artery in dog, rabbit and human fetus. Okajima Folia Anat. Jpn., 47: 193$212,1970$.

14) Martínez, P.: Le sysèma artériel de la base du cerveau et l'origine des artéres hypophysaires chez le chat. Acta Anat. 61: 511$546,1965$.

15) Nickel, R., A. Schummer und E. Seiferle: Lehrbuch der Anatomie der Haustiere. Bd. III, Verlag Paul Parey, Berlin und Hamburg, 106-113, 1976.

16) Nomina anatomica veterinaria: Published by Intern. Comm. on Vetrein. anat. nomen., 2nd ed., Holzhausen, Vienna, 1975.

17) Norris, H.W.: The caroid arteries and their relation to the circles of Willis in the cat. Porc. Iowa Acad. Sci., 13: 25 1-255, 1906.

18) Suzuki, T.: The vascular system of the neck in the dog. I. On the vascular supply of the cervical muscles. Acta Anat. Nippon, 38: 
230-257, 1963 (in Japanese).

19) Suzuki, T.: The vascular system of the neck in the dog. II. On the vascular supply of the pharynx and larynx. Acta Anat. Nippon, 40: 220-230, 1965 (in Japanese).

20) Takemura, A.: The rete mirabile of the maxillary artery in the cat. Okajimas Folia Anat. Jpn., 59: 103-136, 1982.

21) Tandler, J.: Zur vergleichenden Anatomie der Kopfarterien bei den Mammalia. Denkschr. Kais, Akad. Wiss. Mathematischnaturw, Klasse,
Wien, 67: 711-712, 1899.

22) Taniguchi, Y., Y. Ohta and S. Tajiri: New improved method for injection of acrylic resin. Okajimas Folia Anat. Jpn., 24: 259-267, 1952.

23) Taniguchi, Y., Y. Ohta, S. Tajiri, H. Okano and H. Hanai: Supplement to new improved method for injection of acrylic resin. Okajimas Folia Anat. Jpn., 27: 401-406, 1955.

24) Warwick, R. and P.L. Williams: Cray's Anatomy, 35th ed., Longman, London, 1973.

\author{
ap : Ascending pharyngeal artery \\ B : Stylohyoid bone \\ C : Cricopharyngeus muscle \\ ce : External carotid artery \\ ci : Internal carotid artery \\ D : Digastricus muscle \\ di : Digastric branch \\ G : Stylohyoideus muscle \\ H : Hyopharyngeus muscle \\ hy : Hyopharyngeal branch
}

Abbreviations

if : Inferior cervical branch

la : Laryngeal artery

li : Lingual artery

oc : Occipital artery

pt : Palatine branch

$S$ : Stylopharyngeus muscle

st : Stylopharyngeal branch

$\mathrm{T}$ : Thyropharyngeus muscle

th : Thyropharyngeal branch

ve : Levator veli palantine branch

$\mathcal{L}$ : Direction of the snout 


\section{PLATES}




\section{Explanation of Figures}

\section{Plate I}

Fig. 2. Inferior view of the pharynx and fauces of the right side.

Branches of the external carotid (ce) are shown after removal of part of the pharynx, the larynx and the esophagus. The pharyngeal branch $\left(x^{\prime}\right)$ of the vagues nerve $(x)$ is drawn posterosuperiorly. The ascending pharyngeal (ap) arising from the anterior wall of the occipital (oc) passes anteromedially between the vagus and hypoglossal nerves (o) above the external carotid and gives rise to the palatine branch $(\mathrm{pt})$ inferoanteriorly, which supplies the soft palate $(\Delta)$ and the the palatine tonsil $\left({ }^{*}\right) . \times 2.6$

Fig. 3. Superior view of the posterior wall of the pharynx.

The cranial basis and cervical vertebrae are removed except the longi capiti $(0)$ and the internal carotid (ci). The ascending pharyngeal (ap) arises from the superomedial wall of the external carotid (ce) passing between the digastricus (D) and the pharyngeal wall. This artery reaches the lateral wall of the pharynx at the superior margin of the thyropharyngeus $(\mathrm{T})$, where it gives rise to the thy ropharyngeal (th), the hyopharyngeal (hy) and the distal one of the stylopharyngeal (st) branches. The inferior cervical branch (if) arises from the occipital (oc) and gives off small twigs $(\leftrightarrow)$ to the thyropharyngeus. $\times 1.2$.

Fig. 4. Superolateral view of the pharyngeal wall of the left side.

The ascending pharyngeal (ap) arises from the medial wall of the posterior auricular (o) and gives rise to the inferior cervical branch (if). The internal carotid (ci) and the occipital (oc) are cut near their origins. $\times 3.7$.

Fig. 5. Lateral view of the pharyngeal wall of the left side.

The digastric branch (di) arising from the external carotid (di) is cut. The ascending pharyngeal (ap) arises from the ascending palatine (o) of the lingual artery (li), but does not give rise to any branches. $\times 2.8$. 

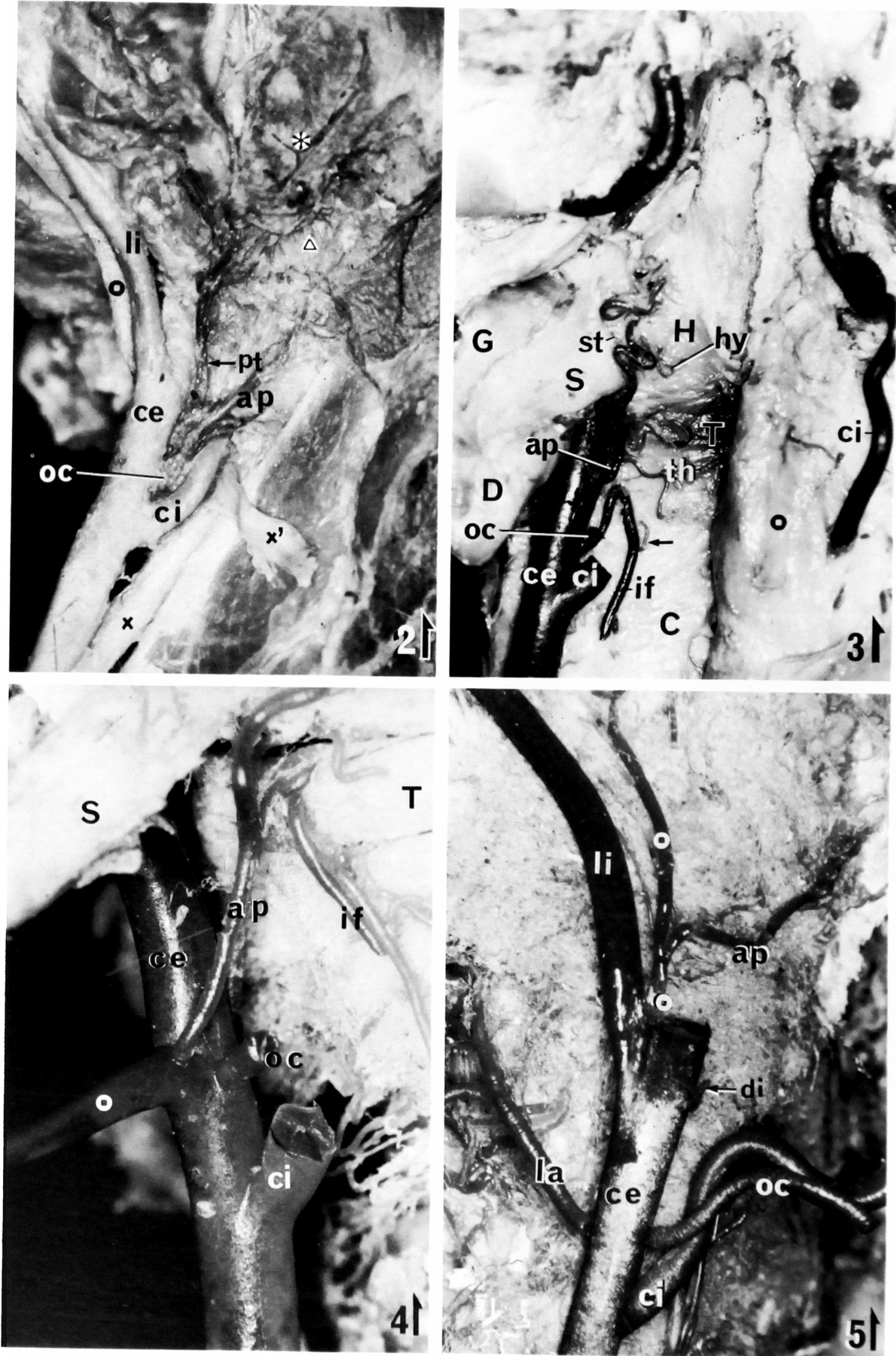


\section{Plate II}

Fig. 6. Superomedial view of the pharyngeal wall of the right side.

The ascending pharyngeal (ap) arises via a common trunk $(\rightarrow)$ with the occipital (oc) from the anterior wall of the internal carotid (ci), and immediately gives rise to the stylopharyngeal branch (st) laterally. $\times 2.9$.

Fig. 7. Superolateral view of the the pharyngeal wall of the right side.

The inferior cervical branch (if) arises from the occipital (oc). The ascending pharyngeal (ap) arising from the external carotid (ce) gives off the digastric branch (di). It passes above the external carotid, giving rise to the stylopharyngeal branch (st), and supplies the origin of the digastricus (D). X4.1.

Fig. 8. Medial view of the median section of the left side.

The ascending pharyngeal (ap) arises from the occipital (oc) and gives rise to the palatine (pt) inferoanteriorly and the digastric (di) branches laterally. This palatine branch gives off a small twig $(\Delta)$ to the hyopharyngeus and stylopharyngeus, and divides in to the anterior $(0)$ and inferior $(x)$ in front of them. The former passes forwards medial to the stylopharyngeus $(G)$ to supply it $(\downarrow)$ and the posterior end of the palatoglossal arch, and the latter supplies the soft palate (xx), (B) Stylohyoid. X2.3.

Fig. 9. Interior view of the posterior wall of the pharynx.

The ascending pharyngeal (ap) passes forwards in the posterolateral wall of the pharynx inferomedial to the tympanic bulla (o) and gives off the stylopharyngeal branch (hy), small twigs $(\Delta)$ to the mucosa between the pharyngeal opening $(X)$ of the auditory tube and the pharyngeal isthmus $\left(x^{\prime}\right)$, and small twig $(\bullet)$ to the periosteum of the bulla. It passes inferomedial to the foramen caroticum externum $(\rightarrow)$ and the pterygoid process $(*)$ up to the pharyngeal fornix. A twig (0) of the inferior cervical branch is well developed but the stylopharyngeal branch (hy) is fine. X1.9. 
The Ascending Pharyngeal Artery of the Dog 255

Plate II

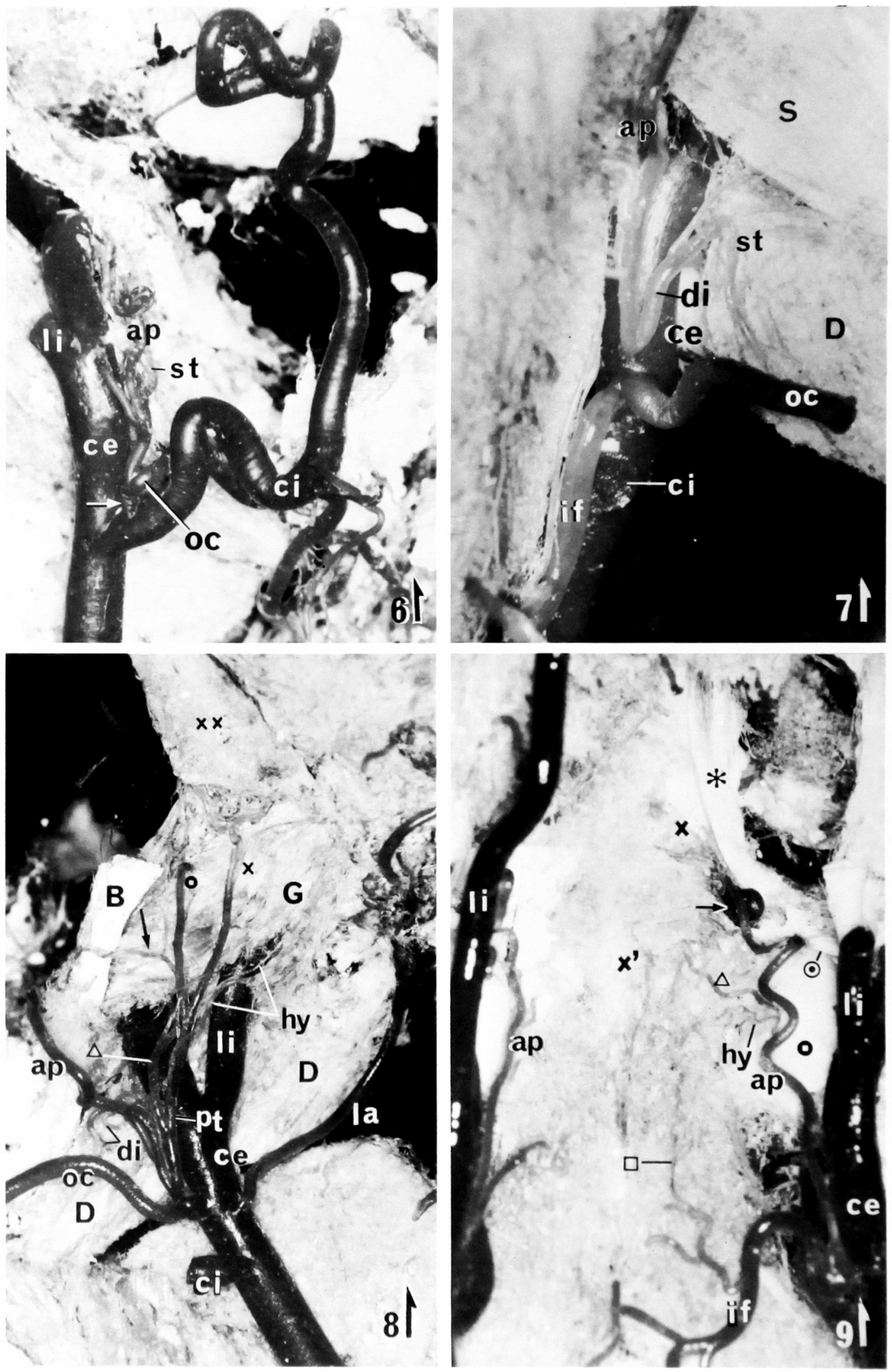




\section{Plate III}

Fig. 10. Superomedial view of the posterior pharyngeal wall of the right side.

The ascending pharyngeal (ap) gives rise to the thyropharyngeal (th) and the hyopharyngeal (hy) branches and a small twig $(x)$ to the posterior wall of the pharynx, which supplies the mucosa between the opening of the auditory tube $(\Delta)$ and the pharyngeal isthmus $(*)$. It also gives rise to the distal one of the stylopharyngeal (st), and the levator veli palatine (ve) branches, and a small twig (o) to the styloglossus. The digastric branch (di) diverges from the external carotid (ce) and supplies the stylopharyngeus (S) and digastricus (removed). $\times 3.1$.

Fig. 11. Superomedial view of the posterior pharyngeal wall of the right side.

The ascending pharyngeal (ap) makes an upward curvature $(\leftrightarrow)$ towards the loop of the internal carotid at the foramen caroticum externum. $\times 2.3$.

Fig. 12. Superomedial view of the posterior pharyngeal wall of the left side.

The ascending pharyngeal (ap) makes an upward curvature $(x)$ at the foramen caroticum externum. This curvature does not intertwine with the loop (o) of the internal carotid, and a small twig ( $\downarrow$ ) from it supplies the vicinity around the foramen. $\times 3.2$.

Fig. 13. Medial view of the ascending pharyngeal of the right side.

The ascending pharyngeal (ap) anastomoses $(\leftarrow)$ with the loop (o) of the internal carotid at the foramen caroticum externum and continues to pass towards the pharyngeal fornix $(x) . \times 2.8$. 

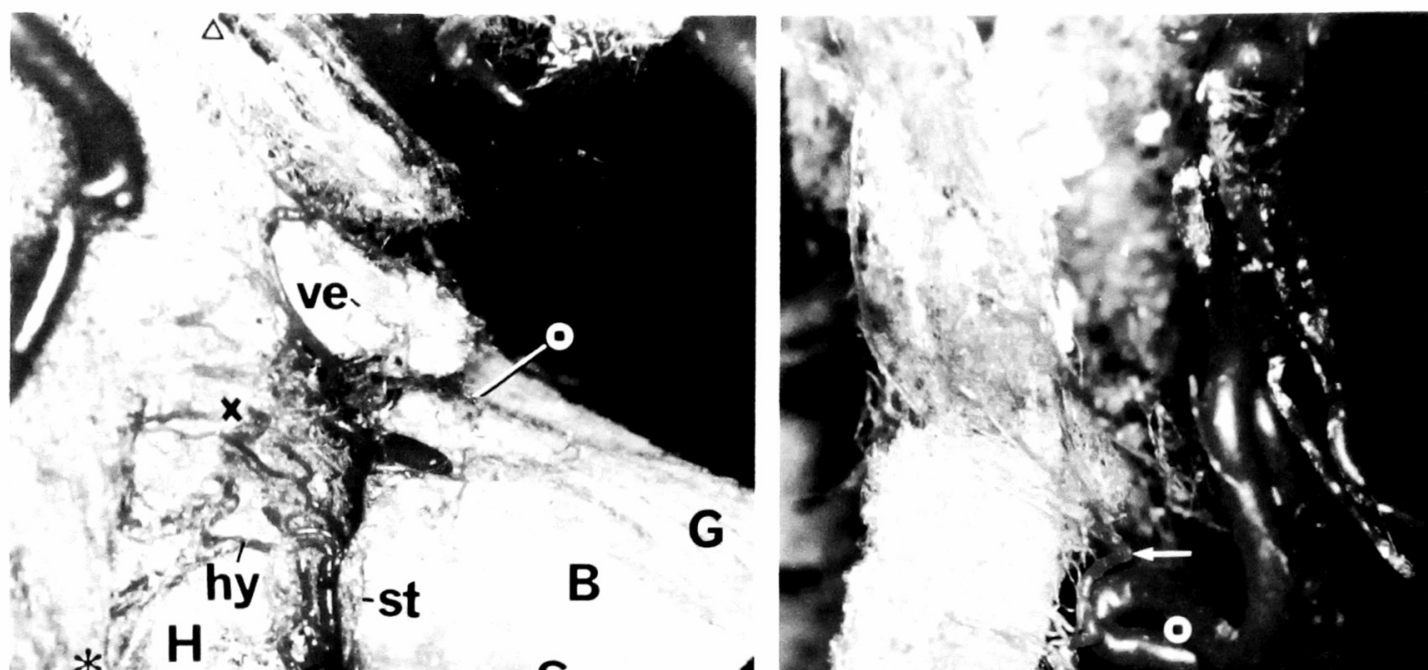

i. hy hy -st

$* * \mathbf{H}$.
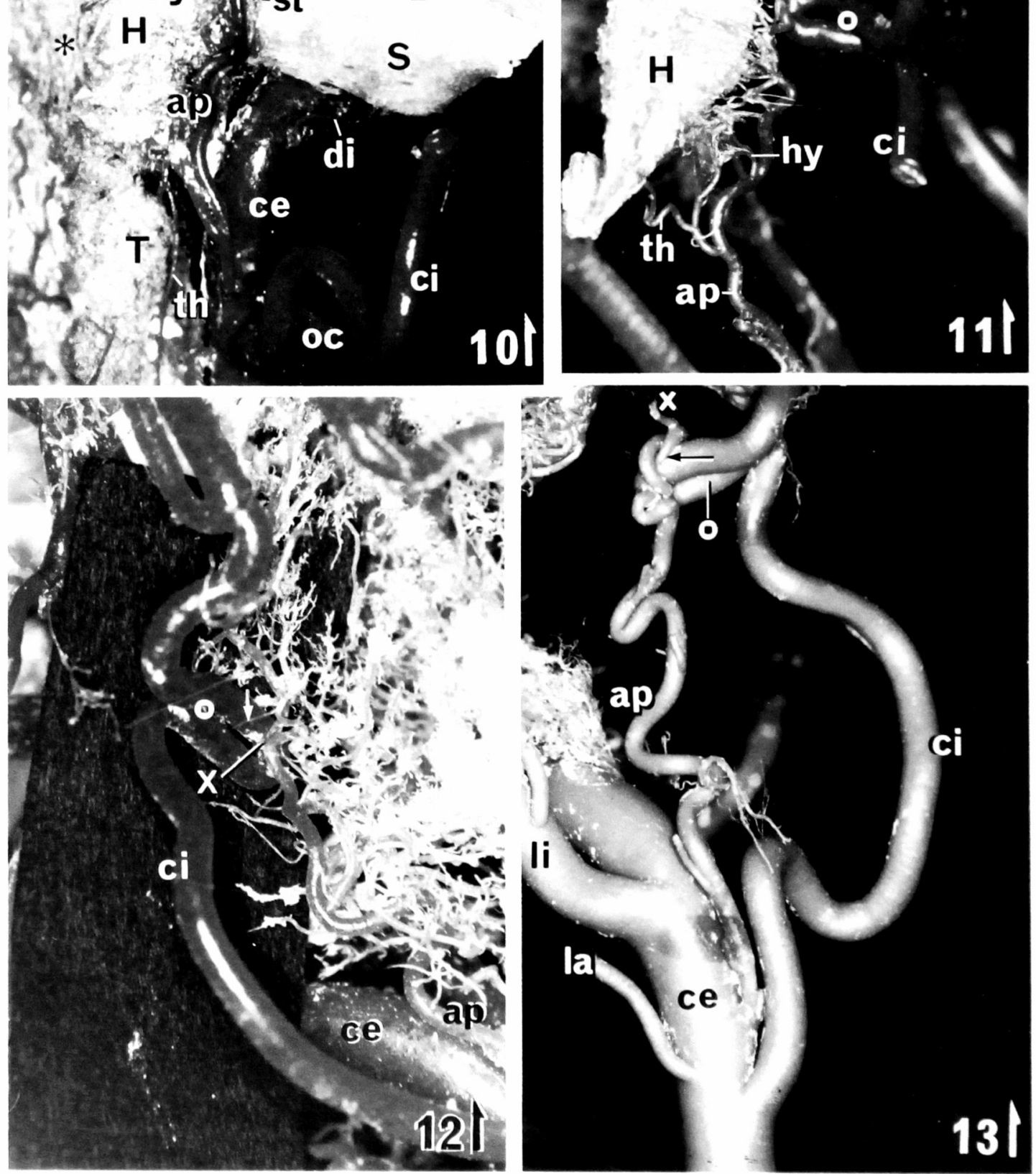


\section{Plate IV}

Fig 14. Superior view of the posterior pharyngeal wall.

The ascending pharyngeal (ap) passes forwards between the pterygoid process (x) and the mucosa of the nasopharynx, and gives off small twigs $(\rightarrow)$ to the mucosa of the pharyngeal fornix forming a network. X1.7.

Fig. 15. Superomedial view of the posterior pharyngeal wall.

The original ascending pharyngeal (ap) arises from the external carotid and terminates after giving rise to the thyropharyngeal (th), the stylopharyngeal (st) and the palatine (pt) branches. An area supposed to be supplied by peripheral branches of this artery in the usual pattern is supplied by a branch arising from the loop of the internal carotid (ci). This branch divides into the anterior (o) and posterior $(x)$. The former is distributed to the mucosa of the nasopharynx, giving rise to the levator veli palatine branch (ve), and the latter passes backwards, giving rise to twigs $(*)$ to the mucosa of the posterior pharyngeal wall, the hyopharyngeal (hy), a twig $(\leftarrow)$ to the styloglossal branches, but does not communicate with the ascending pharyngeal. X2.6.

Fig. 16. Lateral view of the pharynx of the left side.

The inferior cervical branch (if) arises from the cranial thyroid artery (o). ( $\Delta$ ) Thyroid gland. (x) Common carotid artery. $\times 2.1$.

Figs. 17 and 18. Superior views of the posterior wall of the pharynx.

The inferior cervical branch (if) arises from the left extemal carotid (ce) and the right occipital (oc) in Fig. 17, and the ascending pharyngeal (ap) in Fig. 18, passes medially up to the median pharyngeal raphe (broken line), giving off anterior $(\rightarrow)$ and posterior $(\leftrightarrow)$ twigs. The former supplies the thyropharyngeus $(\mathrm{T})$, the hyopharyngeus $(\mathrm{H})$ and the mucosa of the posterior pharyngeal wall, and the latter supplies the longus capitis (o).

In Fig. 17, this branch bends backwards at right angles to pass backwards between the longi capiti (o) of both sides (their insertions are removed) along the pharyngeal raphe and gives offtwigs to the muscles and the longi colli $(\mathrm{x})$ of both sides. In Fig. 18, it supplies the longus capitis of the opposite side and the longi colli. $\times 1.8$ and $\times 1.4$, respectively. 
The Ascending Pharyngeal Artery of the Dog 259

Plate IV

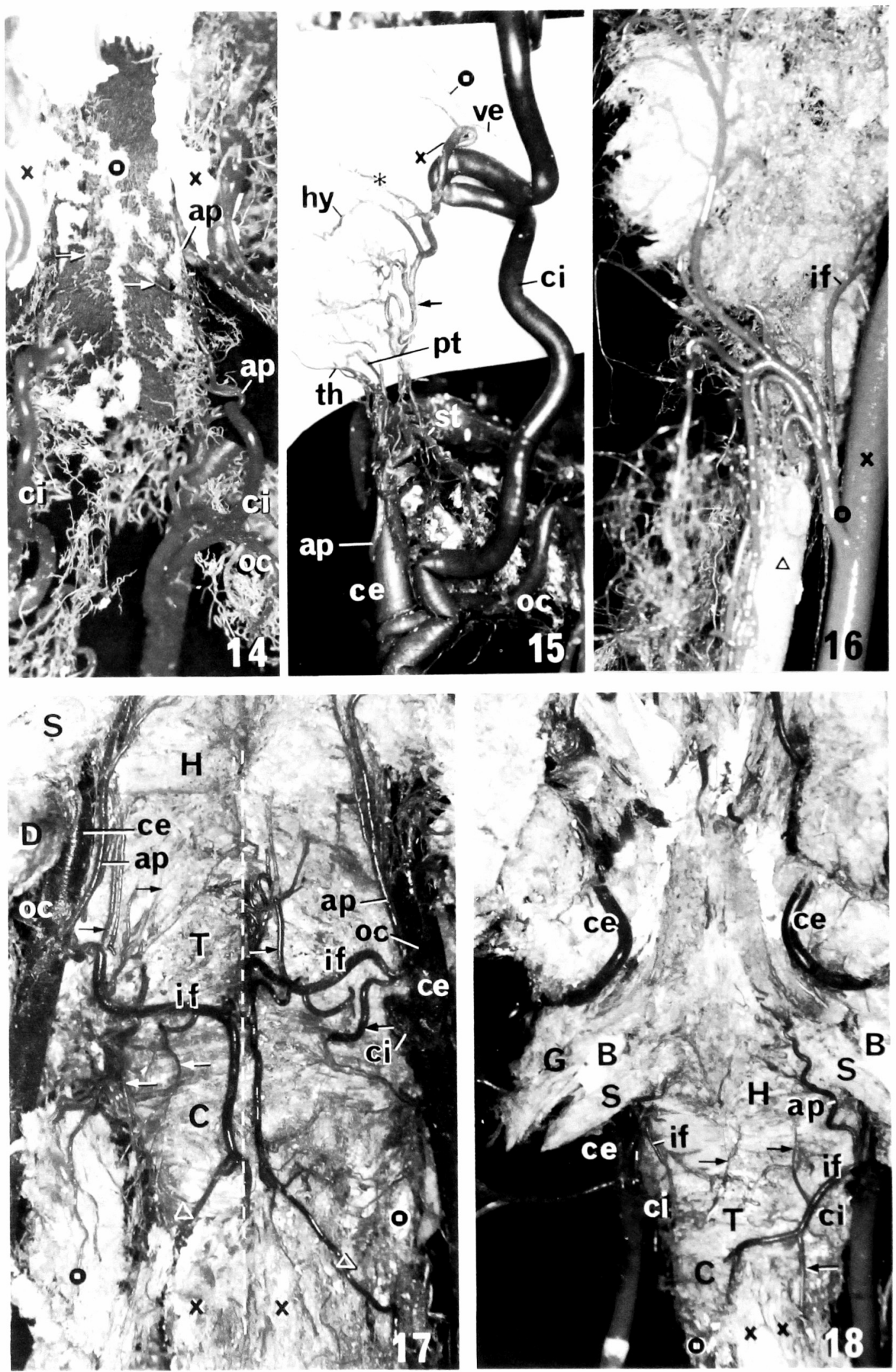

